\title{
An efficient and scalable extraction and quantification method for algal derived biofuel
}

\section{Authors: Egan J. Lohman, Robert D. Gardner, Luke Halverson, Richard E. Macur, Brent M. Peyton, \& Robin Gerlach}

NOTICE: this is the author's version of a work that was accepted for publication in Journal of Microbiological Methods. Changes resulting from the publishing process, such as peer review, editing, corrections, structural formatting, and other quality control mechanisms may not be reflected in this document. Changes may have been made to this work since it was submitted for publication. A definitive version was subsequently published in Journal of Microbiological Methods, 94, 3, September 2013. DOI\# 10.1016/j.mimet.2013.06.007.

Lohman EJ, Gardner RD, Halverson L, Macur RE, Peyton BM, Gerlach R, "An efficient and scalable extraction and quantification method for algal derived biofuel," Journal of Microbiological Methods, September 2013 94(3): 235-244. 


\title{
An efficient and scalable extraction and quantification method for algal derived biofuel
}

\section{Egan J. Lohman, Robert D. Gardner, Luke Halverson, Richard E. Macur, Brent M.}

\author{
Peyton, Robin Gerlach *
}

Montana State University, Department of Chemical and Biological Engineering and Center for Biofilm Engineering, Bozeman, MT 59717, United States

\section{A B S T R A C T}

Microalgae are capable of synthesizing a multitude of compounds including biofuel precursors and other high value products such as omega-3-fatty acids. However, accurate analysis of the specific compounds produced by microalgae is important since slight variations in saturation and carbon chain length can affect the quality, and thus the value, of the end product. We present a method that allows for fast and reliable extraction of lipids and similar compounds from a range of algae, followed by their characterization using gas chromato-graphic analysis with a focus on biodiesel-relevant compounds. This method determines which range of biologically synthesized compounds is likely responsible for each fatty acid methyl ester (FAME) produced; information that is fundamental for identifying preferred microalgae candidates as a biodiesel source. Traditional methods of analyzing these precursor molecules are time intensive and prone to high degrees of variation between species and experimental conditions. Here we detail a new method which uses microwave energy as a reliable, single-step cell disruption technique to extract lipids from live cultures of microalgae. After extractable lipid characterization (including lipid type (free fatty acids, mono-, di- or tri-acylglycerides) and carbon chain length determination) by GC-FID, the same lipid extracts are transesterified into FAMEs and directly compared to total biodiesel potential by GC-MS. This approach provides insight into the fraction of total FAMEs derived from extractable lipids compared to FAMEs derived from the residual fraction (i.e. membrane bound phospholipids, ste-rols, etc.). This approach can also indicate which extractable lipid compound, based on chain length and relative abundance, is responsible for each FAME. This method was tested on three species of microalgae; the marine diatom Phaeodactylum tricornutum, the model Chlorophyte Chlamydomonas reinhardtii, and the freshwater green alga Chlorella vulgaris. The method is shown to be robust, highly reproducible, and fast, allowing for multiple samples to be analyzed throughout the time course of culturing, thus providing time-resolved information regard-ing lipid quantity and quality. Total time from harvesting to obtaining analytical results is less than $2 \mathrm{~h}$.

Keywords:

Triacylglycerol (TAG) - Microalgae - Biodiesel - Fatty acid methyl ester (FAME) Nile Red fluorescence - GC-FID/MS

\section{N T R O D U C T I O N}

Consumption rates of traditional fossil fuels in the United States currently exceed 18 million barrels per day with a significant percent-age being imported from foreign sources (EIA, 2012). The political, economic and environmental controversies over these resources have resulted in increased interest in advanced alternative fuels (Dismukes et al., 2008; Greenwell et al., 2010; Groom et al., 2008; Hill et al., 2006; Sheehan, 1998). Although algae-derived biofuels command a relatively small percentage of this emerging market, they hold great potential for truly displacing traditional sources due to their high biomass productivity, relatively small land mass requirements and high lipid yield (Chisti, 2007; Hu et al., 2008). Further, algal fuels do not directly contend in the "fuel vs. food" debate because they can grow in non-arable environments (Ferrell and Sarisky-Reed, 2010).
Biodiesel is the end result of a transesterification reaction in which lipids such as phospholipids, free fatty acids (FFA), and mono, di, and tri-acylglycerides (MAG, DAG, TAG), derived from plant or animal sources, react with methanol in the presence of heat and base or acid, to produce fatty acid methyl esters (FAMEs) (Laurens et al., 2012a). Biodiesel is considered a "drop-in" fuel since no modifications have to be made to the current distribution infrastructure or diesel combustion engines. Biodiesel has similar combustion properties to petroleum diesel and a higher combustion efficiency than gasoline (Demirbas, 2007).

However, if biodiesel is to replace a large part of petroleum hydro-carbon based fuels, the compositional makeup of biodiesel will be-come highly important since biodiesel can have poorer performance than petroleum-based diesel (Hunter-Cevera et al., 2012). For exam-ple, (i) the viscosity of fully saturated hydrocarbons increases signifi-cantly at low temperatures and can lead to operational issues and (ii) short chain fatty acid methyl esters tend to be more susceptible to oxidation which can lead to corrosion, resulting in reduced engine durability (Xue et al., 2011). Therefore a comprehensive and diverse 
feedstock of lipid precursors along with the derived fatty acid methyl esters will be necessary to achieve the desired properties of the biodiesel fuel (Knothe, 2005).

Traditionally, microalgae species have been screened for strains that produce a high abundance of TAG using fluorometric techniques such as the Nile Red assay (Cooksey et al., 1987) and total lipid extracts have been quantified gravimetrically (Bligh and Dyer, 1959) or by gas chromatography after transesterification (e.g. Guckert and Cooksey, 1990). However, these methods are limited by their inherent inability to identify all, or only those, compounds which may be utilized for fuel. Nile Red, for instance, roughly correlates with the amount of TAG precursors per cell (Chen et al., 2009; Cooksey et al., 1987; Elsey et al., 2007; Gardner et al., 2011, 2013). Hence, Nile Red-based measurements may underestimate the total biofuel potential of algal species that produce high fractions of FFA, MAG, DAG or membrane lipids. Additionally, the Nile Red assay is qualitative (possibly semi-quantitative) and cannot be compared between species. In contrast, gravimetric analysis can overestimate total biofuel potential by including non-fuel components (e.g. chlorophyll) in the total weight (Laurens et al., 2012b). Gas chromatographic analysis of FAMEs has proven to be a reliable method for quantifying total biodiesel potential (Eustance et al., in press; Laurens et al., 2012b), but fails to identify the biological precursor molecules.

Here, a new method is described which allows for high-throughput harvesting and extraction of live cultures by utilizing microwave energy for a one-step cell disruption-and-extraction of lipid precursors (FFA, MAG, DAG, TAG). Microwave energy has recently been shown to be an effective cell disruption technique, generating comparative or better lipid yields than more traditional methods such as sonication or bead beating (Lee et al., 2010; Patil et al., 2012; Prabakaran and Ravindran, 2011). Additionally, extraction of lipids from live culture significantly reduces process time and decreases the potential for degradation of intracellular lipid compounds. A portion of the lipid extract is analyzed by GC coupled with flame ionization detection (GC-FID) to identify the lipid class and carbon chain length of the fatty acid(s). In parallel, a portion of the lipid extract is transesterified and analyzed by GC-MS to identify FAMEs derived from extractable lipid. Additionally, total biodiesel potential is determined by direct in situ transesterification of live cultures. Comparisons can be made between extractable lipid precursors, FAMEs derived from extractable lipids and total biodiesel potential by contrasting the carbon chain length and saturation of each molecule respectively. This approach was demonstrated for three different frequently used microalgae species; the model Chlorophyte Chlamydomonas reinhardtii, the marine diatom Phaeodactylum tricornutum and the freshwater green alga Chlorella vulgaris. These three organisms have been extensively studied (e.g. Gardner et al., 2012; Merchant et al., 2007; Stephenson et al., 2010; Valenzuela et al., 2012) and represent a diverse set of microalgae which are commonly used for biofuel investigations (Gardner et al., 2013; Liu et al., 2011; Spiekermann et al., 2003). The method described herein is relatively simple, fast, utilizes fairly standard equipment, and results in a comprehensive lipid profile within $2 \mathrm{~h}$ of harvesting.

\section{Materials and methods}

\subsection{Microalgae strains}

\subsubsection{Phaeodactylum tricornutum}

P. tricornutum strain Pt-1 (CCMP 2561) (Pt-1) was acquired from the Provasoli-Guillard National Center for Culture of Marine Phytoplankton (East Boothbay, Maine, USA) and accessions of $P$. tricornutum have previously been described (Martino et al., 2007). Pt-1 was cultured on $\mathrm{ASP}_{2}$ medium (Provasoli et al., 1957) amended with $50 \mathrm{mM}$ Tris buffer (Sigma-Aldrich, USA), pKa 7.8, to maintain a stable pH throughout culturing. Cultures were continuously sparged with ambient air and amended with $25 \mathrm{mM}$ of sodium bicarbonate (final concentration) just prior to nitrate depletion in the medium to induce TAG accumulation as demonstrated by Gardner et al. (2012).

\subsubsection{Chlorella vulgaris}

C. vulgaris, UTEX 395 (University of Texas at Austin) was cultured on Bold's basal medium (Nichols and Bold, 1965) with $\mathrm{pH}$ adjusted to 8.7 prior to autoclaving. Cultures were sparged with $5 \% \mathrm{CO}_{2}$ in air during the light hours.

\subsubsection{Chlamydomonas reinhardtii}

C. reinhardtii CC124, obtained from the Chlamydomonas Center (Minnesota State University, Minneapolis MN), was kindly provided by John Peters, Department of Chemistry and Biochemistry at Montana State University, and was cultured on Sager's minimal medium (Harris, 1989). Cultures were sparged with $5 \% \mathrm{CO}_{2}(\mathrm{v} / \mathrm{v})$ until just prior to ammonium depletion, at which time the gas sparge was switched to ambient concentrations of $\mathrm{CO}_{2}(0.04 \% ; \mathrm{v} / \mathrm{v})$ and $50 \mathrm{mM}$ of sodium bicarbonate (final concentration) were added to induce TAG accumulation (Gardner et al., 2013).

\subsection{Culturing conditions}

All organisms were checked for bacterial contamination by inoculation into respective medium supplemented with $0.05 \%$ yeast extract and $0.05 \%$ glucose and incubation in the dark. Experiments were conducted in triplicate batch cultures using $70 \times 500 \mathrm{~mm}$ glass tubes containing $1.2 \mathrm{~L}$ medium submersed in a water bath to control temperature. Rubber stoppers, containing ports for aeration and sampling, were used to seal the tubes. Temperature was maintained at $24{ }^{\circ} \mathrm{C} \pm 1{ }^{\circ} \mathrm{C}$. Light ( $400 \mu \mathrm{mol}$ photons $\mathrm{m}^{-2} \mathrm{~s}^{-1}$ ) was maintained on a 14:10 light-dark cycle using a light bank containing T5 tubes. Aeration ( $400 \mathrm{~mL} \mathrm{~min}^{-1}$ ) was supplied by humidified compressed air (supplemented with $5 \% \mathrm{CO}_{2}(\mathrm{v} / \mathrm{v})$ for $\mathrm{C}$. reinhardtii and $\mathrm{C}$. vulgaris) and controlled using individual rotameters for each bioreactor (Cole-Parmer, USA). ACS grade sodium bicarbonate was used in all experiments involving bicarbonate addition (Sigma-Aldrich, St. Louis, $\mathrm{MO})$.

\subsection{Culture analysis}

Cell concentrations were determined using an optical hemacytometer with a minimum of 400 cells counted per sample for statistical reliability. Cell dry weights (CDWs) for $C$. reinhardtii and $C$. vulgaris were determined by harvesting $30 \mathrm{~mL}$ of culture into a tared $50 \mathrm{~mL}$ Falcon tube (Fisher Scientific, Palatine, IL) followed by centrifugation at $4800 \times g$ and $4{ }^{\circ} \mathrm{C}$ for $10 \mathrm{~min}$ (Thermo Scientific, Sorvall Legend XTR, Waltham, MA). The concentrated biomass was rinsed with deionized $\mathrm{H}_{2} \mathrm{O}\left(\mathrm{diH}_{2} \mathrm{O}\right), 18 \mathrm{M} \Omega$, to remove media salts and excess bicarbonate, before centrifuging again. Remaining algae pellets were frozen and lyophilized (Labconco lyophilizer, Kansas City, MO) for $48 \mathrm{~h}$. CDWs were calculated by subtracting the weight of the biomass-free Falcon tube from the weight of the Falcon tube with freeze-dried biomass.

CDWs for $P$. tricornutum were determined by filtering $10 \mathrm{~mL}$ of culture using $1 \mu \mathrm{m}$ pore size glass fiber filters (Fisher Scientific) to collect the biomass. The biomass was washed with $\mathrm{diH}_{2} \mathrm{O}$ to remove media salts and excess bicarbonate. Algal cells were dried at $70{ }^{\circ} \mathrm{C}$ until the weight of the filter (plus biomass) remained constant. CDWs were calculated by subtracting the dry weight of the clean filter from the oven-dried weight of the filter with biomass. This method was employed for the diatom due to the concern that the fragility of the organism's silicon-based frustules may result in cell disruption during the centrifugation and lyophilization steps utilized for the Chlorophytes, thereby underestimating overall CDWs. This technique was not employed for the Chlorophytes because it has been shown by 
us and others (Laurens et al., 2012a) that the freeze drying method is more reliable for green microalgae.

\subsection{Analysis of media components}

Medium pH was measured using a standard bench top $\mathrm{pH}$ meter. Ammonium and nitrate concentrations were measured using Nessler reagent (Hach, Loveland, CO) and ion chromatography (Dionex, Sunnyvale, CA), respectively, using previously described protocols (Gardner et al., 2013).

\subsection{Harvesting}

At the end of each experiment, cultures were transferred to a graduated cylinder and total harvest volume was recorded. Two aliquots of $45 \mathrm{~mL}$ were dispensed into $50-\mathrm{mL}$ Falcon tubes (Fisher Scientific, Palatine, IL) and centrifuged (Thermo Scientific, Sorvall Legend XTR, Waltham, MA) at $5800 \times \mathrm{g}$ and $4{ }^{\circ} \mathrm{C}$ for $10 \mathrm{~min}$. Concentrated biomass was then transferred to Pyrex test tubes with Teflon lined screw caps (Kimble-Chase, Vineland, NJ) for microwave extraction of lipid precursors (Section 2.6.1) and direct in situ transesterification for total biodiesel potential (Section 2.7), respectively. The remaining $\sim 1 \mathrm{~L}$ of culture was centrifuged (Thermo Scientific, Sorvall Legend XTR, Waltham, MA) at $5800 \times \mathrm{g}$ and $4{ }^{\circ} \mathrm{C}$ for $10 \mathrm{~min}$. The supernatant was discarded and the remaining concentrated biomass was combined in a $50 \mathrm{~mL}$ Falcon tube, washed with $\mathrm{diH}_{2} \mathrm{O}$, re-centrifuged, and the supernatant discarded. The washed biomass pellets were frozen at $-80{ }^{\circ} \mathrm{C}$, lyophilized, and stored at $-20{ }^{\circ} \mathrm{C}$ for subsequent cell disruption/lipid extraction method comparisons (Section 2.6).

\subsection{Cell disruption and extraction of lipids}

Six different cell disruption and lipid extraction techniques were tested in biological triplicate to compare their extraction yields against yields from microwave extraction on live cultures. Unless otherwise stated, all methods were performed using approximately $30 \mathrm{mg}$ of dried biomass, and the final extract was supplemented with $10 \mu \mathrm{L} / \mathrm{mL}$ of a $10 \mathrm{mg} / \mathrm{mL}$ internal standard mix (isooctane in chloroform) to monitor instrument performance. All mixtures involving solvent and heat were carefully sealed in Pyrex test tubes with Teflon lined screw caps (Kimble-Chase, Vineland, NJ). Final extracts were analyzed for lipid precursors by gas chromatography-flame ionization detection (GC-FID) (Section 2.9.2).

\subsubsection{Microwave extraction of lipid from wet biomass}

$45 \mathrm{~mL}$ of culture were ( 45 milliliters) transferred into a $50 \mathrm{~mL}$ Falcon tube and centrifuged at $4800 \times g$ and $4{ }^{\circ} \mathrm{C}$ for $10 \mathrm{~min}$. The supernatant was discarded and the pellets were re-suspended in $3 \mathrm{~mL}$ $\mathrm{diH}_{2} \mathrm{O}$ to facilitate transfer from Falcon tubes to screw-cap glass tubes for subsequent lipid extraction. Three $\mathrm{mL}$ of chloroform were added to the algal slurry in the test tubes, and the mixture was homogenized by vortexing for $10 \mathrm{~s}$. Caps were securely fastened and samples were microwaved (Sharp Carousel, Mahwah, NJ) at $1000 \mathrm{~W}$ on power level $1\left(\sim 100{ }^{\circ} \mathrm{C}\right.$ and $\left.2450 \mathrm{MHz}\right)$ for $1 \mathrm{~min}$ and then allowed to cool for $5 \mathrm{~min}$. This process of vortexing for $10 \mathrm{~s}$, microwaving for $1 \mathrm{~min}$ and cooling for $5 \mathrm{~min}$ was repeated until optimal extraction efficacy was established for each culture (Supplemental data). A total of 3 min microwave exposure was required for samples of $P$. tricornutum and $C$. reinhardtii. Samples of $C$. vulgaris required a total of $10 \mathrm{~min}$ microwave exposure to completely disrupt cells and release lipids into the organic solvent. Transmitted light microscopy was used to verify complete disruption of cells, and epifluorescence microscopy was used to verify all extractable lipid (stained with Nile Red) had been released into the organic solvent (Nikon Eclipse E800).
It should be noted that extreme caution should be taken when applying microwave energy to an organic solvent under high heat and pressure. To address this inherent safety concern this method has since been modified by adding only $5 \mathrm{~mL} \mathrm{diH}_{2} \mathrm{O}$ to the algal pellet before transferring the slurry to screw cap test tubes, and test tubes were further secured by placing them in a microwaveable Tupperware container. Samples were then microwaved at $1000 \mathrm{~W}$ power level 4 $(2450 \mathrm{MHz}$ ) for a continuous $5 \mathrm{~min}$ and allowed to cool. Three $\mathrm{mL}$ of chloroform were added to each test tube when they had reached room temperature. Test tubes were vortexed for $10 \mathrm{~s}$ and heated at $90{ }^{\circ} \mathrm{C}$ for 5 min to improve partitioning of the extracted lipids into the organic phase. Equivalent results were obtained with both versions of the method. The latter (i.e. water only-based extraction) being inherently safer, it is the recommended approach. In either case, samples were then centrifuged at $1200 \times g$ for 2 min to enhance phase separation. One $\mathrm{mL}$ of the organic phase was removed from the bottom of the test tube using a glass syringe and transferred to a $2 \mathrm{~mL} \mathrm{GC}$ vial (Fisher Scientific, Palatine, IL) for GC-FID analysis and subsequent transesterification (Sections 2.9.2 and 2.8, respectively).

\subsubsection{Microwave extraction of lipids from dry biomass}

Microwave extraction of lipids from dry biomass was conducted as described in Section 2.6.1 except $\sim 30 \mathrm{mg}$ of dried algae biomass were used instead of live culture. Samples of $P$. tricornutum and $C$. vulgaris were extracted using the optimized microwave extraction technique with just $\mathrm{diH}_{2} \mathrm{O}$ and no organic solvent during the microwave step. Samples of $C$. reinhardtii were collected before the optimized method was established; therefore they were extracted with $\mathrm{diH}_{2} \mathrm{O}$ and solvent together in the microwave extraction step.

\subsubsection{Sonication extraction of lipids from dry biomass}

Dried biomass was combined with $3 \mathrm{~mL}$ of chloroform in a disposable $15 \mathrm{~mL}$ boro-silicate test tube. Samples were sonicated with a Branson S-450D sonifier equipped with a microtip probe set to $80 \mathrm{~W}$ (Branson, Danbury, CT) for six $20 \mathrm{~s}$ pulses, with each pulse followed by a $1 \mathrm{~min}$ cool down period in ice water. Total sonication time was $2 \mathrm{~min}$. Samples were then centrifuged at $1200 \times \mathrm{g}$ for $2 \mathrm{~min}$ to pellet the residual biomass. One $\mathrm{mL}$ of the organic phase was removed from the test tube using a glass syringe and transferred to a $2 \mathrm{~mL} \mathrm{GC}$ vial for GC-FID analysis.

\subsubsection{Bead beating extraction of lipids from dry biomass}

Dried biomass was combined with $1 \mathrm{~mL}$ of chloroform in a $1.5 \mathrm{~mL}$ stainless steel bead beating microvial with silicone cap (BioSpec Products, Bartlesville, OK). Three types of beads ( $0.6 \mathrm{~g}$ of $0.1 \mathrm{~mm}$ zirconium/silica beads, $0.4 \mathrm{~g}$ of $1.0 \mathrm{~mm}$ glass beads, two $2.7 \mathrm{~mm}$ glass beads) were added to each vial before capping. A FastPrep bead beater (Bio101/Thermo Savant, Carlsbad, CA) was used to agitate the vials for six $20 \mathrm{~s}$ pulses at power level 6.5 followed by a $1 \mathrm{~min}$ cool down period between pulses. Total bead beating exposure time was $2 \mathrm{~min}$. The mixture of solvent, residual biomass and beads was then transferred to a disposable $15 \mathrm{~mL}$ boro-silicate test tube, and the steel microvial was rinsed twice with $1 \mathrm{~mL}$ of chloroform, which was also added to the test tube, bringing the total solvent volume to $3 \mathrm{ml}$. Samples were then centrifuged at $1200 \times \mathrm{g}$ for $2 \mathrm{~min}$ to pellet the residual biomass. One $\mathrm{mL}$ of the organic phase was removed from the bottom of the test tube using a glass syringe and transferred to a $2 \mathrm{~mL} \mathrm{GC}$ vial for GC-FID analysis.

\subsubsection{Heat induced extraction of lipids from dry biomass}

Dried biomass was combined with $3 \mathrm{~mL}$ of chloroform and $3 \mathrm{~mL}$ $\mathrm{diH}_{2} \mathrm{O}$ in a test tube. Samples were homogenized by vortexing for $10 \mathrm{~s}$. Caps were securely fastened to test tubes and samples were heated in an oven at $95-100{ }^{\circ} \mathrm{C}$ for $1 \mathrm{~h}$ with vortexing every $10-15 \mathrm{~min}$. Samples were then centrifuged at $1200 \times g$ for 2 min to enhance phase separation. One $\mathrm{mL}$ of the organic phase was removed from the bottom of the 
test tube using a glass syringe and transferred to a $2 \mathrm{~mL} \mathrm{GC}$ vial for GCFID analysis.

\subsubsection{Bligh and Dyer extraction of lipid from dry biomass}

The modified Bligh and Dyer method (as described by Guckert et al. (1988), without phosphate buffer) was used without any additional physical cell disruption steps. Briefly $\sim 50 \mathrm{mg}$ of dry biomass from each of the three organisms in triplicate was transferred to Pyrex test tubes with Teflon lined screw caps. $1.5 \mathrm{~mL}$ of chloroform and $3 \mathrm{~mL}$ of methanol were added to each test tube and samples were homogenized by vortexing for $10 \mathrm{~s}$. Caps were securely fastened, samples were placed horizontally on a shaker table and allowed to mix continuously for $18 \mathrm{~h}$. $1.5 \mathrm{~mL} \mathrm{diH}_{2} \mathrm{O}$ and $1.5 \mathrm{~mL}$ chloroform were then added, and samples were vortexed for $10 \mathrm{~s}$ before being centrifuged at $1200 \times \mathrm{g}$ for $2 \mathrm{~min}$ to enhance phase separation. One $\mathrm{mL}$ of the chloroform phase was removed from the bottom of the test tube using a glass syringe and transferred to a $2 \mathrm{~mL}$ GC vial for GC-FID analysis.

\subsection{Direct in situ transesterification for FAME analysis}

Direct in situ transesterification of live cultures was conducted using a previously described protocol (Griffiths et al., 2010) with modifications. FAME composition was analyzed using gas chromatographymass spectroscopy detection (GC-MS) (Section 2.9.3). Briefly, $45 \mathrm{~mL}$ of culture were transferred into a $50 \mathrm{~mL}$ Falcon tube and centrifuged at $4800 \times \mathrm{g}$ and $4{ }^{\circ} \mathrm{C}$ for $10 \mathrm{~min}$. The supernatant was discarded and the pellets were re-suspended in $3 \mathrm{~mL} \operatorname{diH}_{2} \mathrm{O}$ to facilitate transfer from Falcon tubes to screw-cap glass tubes for subsequent transesterification. The tubes were centrifuged at $1200 \times g$ to remove as much water from the remaining biomass as possible. One $\mathrm{mL}$ of toluene and $2 \mathrm{~mL}$ sodium methoxide (Fisher Scientific, Pittsburgh PA) were added to each test tube along with $10 \mu \mathrm{L}$ of a $10 \mathrm{mg} / \mathrm{mL}$ standard mix (C11:0 and C17:0 TAG) to monitor transesterification efficiency of the TAG into FAMEs. Samples were heated in an oven for $30 \mathrm{~min}$ at $90{ }^{\circ} \mathrm{C}$ and vortexed every $10 \mathrm{~min}$. Samples were allowed to cool to room temperature before $2 \mathrm{~mL}$ of $14 \%$ boron tri-fluoride in methanol (Sigma-Aldrich, St. Louis, MO) were added and samples were heated again for an additional $30 \mathrm{~min}$. Samples were again allowed to cool before $10 \mu \mathrm{L}$ of a $10 \mathrm{mg} / \mathrm{mL}$ of C23:0 FAME were added to assess the completeness of partitioning FAMEs into the organic phase. Additionally, $0.8 \mathrm{~mL}$ of hexane and $0.8 \mathrm{~mL}$ of a saturated salt water solution $(\mathrm{NaCl}$ in $\mathrm{diH}_{2} \mathrm{O}$ ) were added. Samples were heated for $10 \mathrm{~min}$ to facilitate FAME partitioning into the organic phase, vortexed for $10 \mathrm{~s}$ and centrifuged at $1200 \times g$ for $2 \mathrm{~min}$ to enhance phase separation. One $\mathrm{mL}$ of the organic phase was removed from the top layer using a glass syringe and transferred to a $2 \mathrm{~mL} \mathrm{GC}$ vial for GC-MS analysis.

\subsection{Transesterification of extractable lipids from wet biomass}

Lipids extracted from wet biomass (described in Section 2.6.1) were transesterified for FAME analysis. Briefly, $0.5 \mathrm{~mL}$ of the extract was removed from the GC vial and transferred to a screw-cap glass tube. One half $\mathrm{mL}$ of a $5 \% \mathrm{HCl}$ in methanol mixture was added to each test tube along with $10 \mu \mathrm{L}$ of a $10 \mathrm{mg} / \mathrm{mL}$ standard mix (C11:0 and C17:0 TAG) to assess transesterification efficiency. Samples were capped with a Teflon lined screw cap, heated for $1 \mathrm{~h}$ at $90{ }^{\circ} \mathrm{C}$ and vortexed every $10 \mathrm{~min}$. Samples were allowed to cool to room temperature before $0.5 \mathrm{~mL}$ of a $15 \%$ salt water solution $\left(\mathrm{NaCl}\right.$ in $\left.\mathrm{diH}_{2} \mathrm{O}\right)$ was added along with $10 \mu \mathrm{L}$ of $10 \mathrm{mg} / \mathrm{mL}$ C23:0 FAME to assess completeness of FAME partitioning into the organic phase. Samples were heated for an additional $10 \mathrm{~min}$ to help partition FAMEs into the organic phase, vortexed for $10 \mathrm{~s}$ and centrifuged at $1200 \times \mathrm{g}$ for $2 \mathrm{~min}$ to enhance phase separation. One $\mathrm{mL}$ of the organic phase was removed from the bottom organic layer using a glass syringe and transferred to a $2 \mathrm{~mL}$ GC vial for GC-MS analysis.

\subsection{Lipid analysis}

\subsubsection{Nile Red}

Cellular TAG accumulation was monitored throughout the experiments using the Nile Red (9-diethylamino-5H-benzo $(\alpha)$ phenoxazine5-one) (Sigma-Aldrich, St. Louis, MO) fluorescence method (Cooksey et al., 1987), which has become a generally accepted screening method for analyzing TAG in algal cultures both in academia and industry (e.g. Chen et al., 2009; Cooksey et al., 1987; da Silva et al., 2009; Elsey et al., 2007). Furthermore, Nile Red fluorescence has been correlated to TAG content using gas chromatography (GC) analysis on extracted lipid from C. reinhardtii, $\mathrm{r}^{2}=0.998$ (Gardner et al., 2013). Briefly, $1 \mathrm{~mL}$ aliquots were removed from cultures and assayed directly with Nile Red ( $4 \mu \mathrm{L}$ from $250 \mu \mathrm{L} / \mathrm{mL}$ in acetone) or by diluting 1:5 with $\mathrm{diH}_{2} \mathrm{O}$ or salt water, for freshwater or marine cultures respectively, before staining with Nile Red ( $20 \mu \mathrm{L}$ from $250 \mu \mathrm{L} / \mathrm{mL}$ in acetone). To maintain linearity of the Nile Red assay, dilution was required when population counts exceeded $1 \times 10^{7}$ cells $/ \mathrm{mL}$. Total Nile Red fluorescence was quantified on a microplate reader (Bio-Tek, USA) utilizing a monochromator set to $480 / 580 \mathrm{~nm}$ excitation/emission wavelengths. A baseline sensitivity setting of 50 was experimentally determined to maximize the signal-to-noise ratio, while accommodating fluorescent level changes over 10,000 units. To minimize fluorescence spillover, black walled 96 well plates were loaded with $200 \mu \mathrm{L}$ of sample. Unstained samples were used for background medium and cellular autofluorescence correction.

\subsubsection{GC-FID}

GC-FID (Agilent 6890N, Santa Clara, CA) analysis was conducted using 1- $\mu \mathrm{L}$ splitless injections onto a $15 \mathrm{~m}$ (fused silica) RTX biodiesel column (Restek, Bellefonte, PA). The initial column temperature was held at $100{ }^{\circ} \mathrm{C}$ for $1 \mathrm{~min}$, before being increased to $370{ }^{\circ} \mathrm{C}$ at a rate of $10{ }^{\circ} \mathrm{C} \mathrm{min}^{-1}$. The injector temperature was held constant at $320^{\circ} \mathrm{C}$. Helium was used as the carrier gas and column flow was held at $1.3 \mathrm{~mL} \mathrm{~min}^{-1}$ for $22 \mathrm{~min}$, increased to $1.5 \mathrm{~mL} \mathrm{~min}^{-1}$, held for $2 \mathrm{~min}$, increased to $1.7 \mathrm{~mL} \mathrm{~min}^{-1}$ and held for $12 \mathrm{~min}$. All flow rate increases were set to $0.2 \mathrm{~mL} \mathrm{~min}^{-2}$. Calibration curves were constructed for each of the following standards: C10:0, C12:0, C14:0, C16:0, C18:0, C20:0 FFA; C12:0, C14:0, C16:0, C18:0 MAG; C12:0, C14:0, C16:0, C18:0 DAG; and C11:0, C12:0, C14:0, C16:0, C17:0, C18:0, C20:0, C22:0 TAG (Sigma-Aldrich, St. Louis, MO) for quantification $\left(r^{2}>0.99\right)$. This GC method allows for an estimate of the amounts of FFA, MAG, DAG and TAG in a single analysis (Fig. 1a).

\subsubsection{GC-MS}

GC-MS analysis was performed according to a previously published protocol (Bigelow et al., 2011). Briefly, $1 \mu \mathrm{L}$ splitless injections were performed via an autosampler into a GC-MS (Agilent 6890N GC and Agilent 5973 Networked MS) equipped with a $30 \mathrm{~m} \times 0.25 \mathrm{~mm}$ Agilent HP-5MS column (0.25 $\mu \mathrm{m}$ film thickness). The injector temperature was $250{ }^{\circ} \mathrm{C}$ and the detector temperature was $280^{\circ} \mathrm{C}$. The initial column temperature was $80{ }^{\circ} \mathrm{C}$ and was increased to $110{ }^{\circ} \mathrm{C}$ at a rate of $8.0{ }^{\circ} \mathrm{C} \mathrm{min}-1$, immediately followed by a ramp at $14.0{ }^{\circ} \mathrm{C} \mathrm{min}^{-1}$ to a final temperature of $310^{\circ} \mathrm{C}$ which was held for 3 min before run termination. Helium was used as the carrier gas and column flow was held at $0.5 \mathrm{~mL} \mathrm{~min}^{-1}$. Quantities of FAMEs were determined by quantifying each response peak with the nearest eluting calibration standard based on retention time, using MSD ChemStation software (Ver. D.02.00.275), with additional analyses performed using a custom program described in Section 2.9.4. A 28-component fatty acid methyl ester standard prepared in methylene chloride ("NLEA FAME mix"; Restek, Bellefonte, PA) was used for GC-MS retention time identification and response curve generation $\left(\mathrm{r}^{2}>0.99\right)$. It should be noted that C18:1, C18:2 and C18:3 co-elute on the column used and have similar fragmentation patterns. They were therefore quantitated together as $\mathrm{C} 18: 1-3$. 


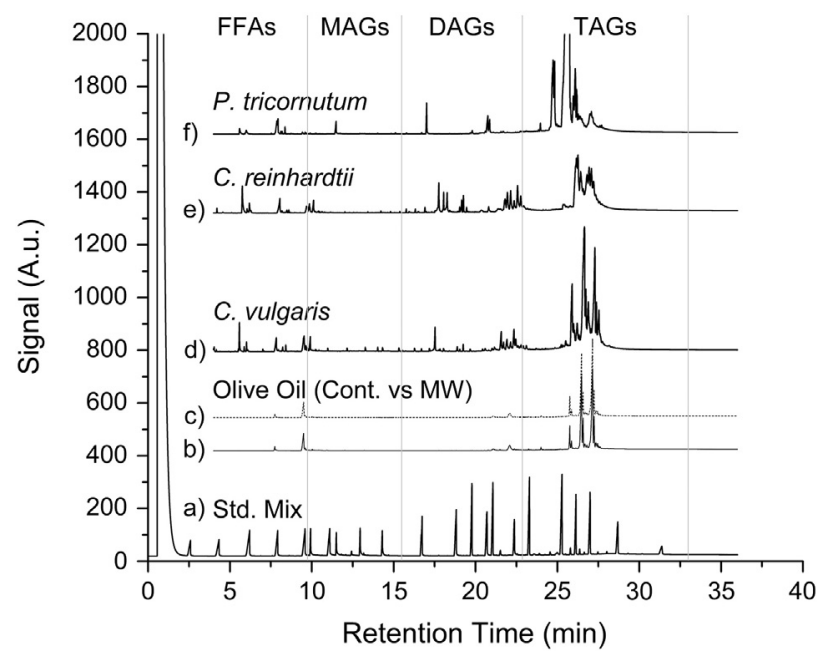

Fig. 1. GC-FID chromatograms: (a) Standard mix of 22 analytical grade lipid standards (0.1 mg/mL); from left to right - C10:0, C12:0, C14:0, C16:0, C18:0 FFA, C12:0 MAG, C20:0 FFA, C14:0, C16:0, C18:0 MAG, C12:0, C14:0 DAG, C11:0 TAG, C16:0 DAG C12:0 TAG, C18:0 DAG, C14:0, C16:0, C17:0, C18:0, C20:0, C22:0 TAG. (b) Olive oil $(1 \mathrm{mg} / \mathrm{mL}$ ) was used as a control (black line) against (c) a sample of the same concentration which was microwaved for $10 \mathrm{~min}$ (dashed line) to assess the potential for thermal degradation of TAG. Lipid extracted via microwave energy from (d) C. vulgaris, (e) C. reinhardtii and (f) P. tricornutum. Chromatograms are offset to allow for alignment with standards.

\subsubsection{Lipid quantification and analysis}

Lipid quantification was performed using a custom program developed specifically for this purpose. Chromatogram data from the GC-FID and GC-MS were exported from the instrument software (Chemstation Ver. B.02.01-SR1) as a Microsoft Excel spreadsheet. The spreadsheet was then imported into a web-based software application written in Microsoft's ASP.NET framework using C\# and MVC as the coding language and paradigm, respectively. Data were stored with unique identifiers in a Microsoft SQL database. Six point calibration curves were constructed using the LINEST function which is built into the ASP.NET framework library. Chromatogram peaks were quantified based on the closest standard, as determined by retention time of the sample peak and standard peak, respectively. All chromatograms were manually integrated and inspected prior to export to ensure accuracy and reliability. Manual calculations were performed periodically using Excel to verify software results.

\subsubsection{Control samples}

Olive oil controls were analyzed by GC-FID to verify no thermal degradation of TAG was occurring when samples were exposed to microwave energy. Olive oil is predominantly comprised of $C_{16}$ and $\mathrm{C}_{18}$ TAG compounds (Kiritsakis et al., 1998). A stock solution of olive oil dissolved in chloroform $\left(1 \mathrm{mg} \mathrm{mL}^{-1}\right)$ was prepared, and aliquots ( $\mathrm{n}=3$ ) were run directly on the GC-FID as a control (Fig. 1b). To verify thermal degradation was not occurring, $3 \mathrm{~mL}$ of the stock solution were transferred to a Pyrex test tube with Teflon lined screw caps and an additional $3 \mathrm{~mL}$ of $\mathrm{diH}_{2} \mathrm{O}$ were added. Samples $(\mathrm{n}=3$ ) were homogenized by vortexing for $10 \mathrm{~s}$, caps were securely fastened, samples microwaved (Sharp Carousel, Mahwah, NJ) at $1000 \mathrm{~W}$ on power level $1\left(\sim 100{ }^{\circ} \mathrm{C}\right.$ and $\left.2450 \mathrm{MHz}\right)$ for $1 \mathrm{~min}$ and then allowed to cool for $5 \mathrm{~min}$. This process of vortexing for $10 \mathrm{~s}$, microwaving for $1 \mathrm{~min}$ and cooling for 5 min was repeated 10 times, for a total of 10 min exposure to microwave energy. Samples were then centrifuged at $1200 \times \mathrm{g}$ for 2 min to enhance phase separation. One $\mathrm{mL}$ of the organic phase was removed from the bottom of the test tube using a glass syringe and transferred to a $2 \mathrm{~mL} \mathrm{GC}$ vial (Fisher Scientific, Palatine, IL) for GC-FID analysis (Fig. 1c).

\subsubsection{Statistical analysis}

A "two one-sided tests" (TOST) procedure (Richter and Richter, 2002) was performed on the control samples described in Section 2.9.5 to determine statistical equivalency between treated and untreated samples. Equivalence was determined for each response peak based on peak area using $n=3$ samples for each group. The TOST procedure requires an acceptance parameter " $\theta$ " to represent the hypothesized mean difference boundary. Sample means are considered equivalent if $\left|\mu_{1}-\mu_{2}\right| \leq \theta$ with a $95 \%$ confidence interval. Statistical parameters were set at: $\theta=$ $0.5, \alpha=0.05$.

\section{Results and discussion}

\subsection{Chromatograph calibration, quantification and data compilation}

The quality of the results obtained using the methods described in this paper relies heavily on proper calibration, chromatogram quantification, quality control and quality assurance. Fig. 1 depicts GC-FID chromatograms for a surrogate mix of calibration standards (Fig. 1a), two olive oil standards (to check for the potential of thermal degradation during microwave treatment; Fig. 1b, c), and samples from each of the three organisms used in this study (Fig. 1d, e, f). The surrogate mix of standards is comprised of twenty two analytical grade lipid standards; six free fatty acids (C10:0-C20:0), four monoacylglycerides (C12:0-C18:0), four diacylglycerides (C12:0$\mathrm{C} 18: 0)$, and eight triacylglycerides (C11:0-C22:0). All of these standards are fully saturated and of even chain length, except for the C11:0 and C17:0 TAG. Six different calibration standard concentrations $(0.005,0.01,0.05,0.1,0.25$ and $0.5 \mathrm{mg} / \mathrm{mL})$ were used to create the calibration curves for each compound listed above. Regression coefficients for each linear calibration curve were $r^{2}>0.99$. Excellent peak shape and resolution were achieved for each of the standards in the mix (Fig. 1a). The algae extract chromatograms exhibit more noise, presumably due to a range of different lipids (chain length and saturation) being produced. As an example, consider the TAG range for $C$. vulgaris (Fig. 1d). The increase in baseline response during retention times of approximately $25-30 \mathrm{~min}$ is likely the result of the presence of a number of TAG with different combinations of fatty acids of different chain lengths per molecule of TAG. In comparison, the chromatogram of olive oil has a mostly flat baseline and exhibits only three groups of peaks in the TAG region. Olive oil consists predominantly of TAG with fatty acid chains consisting of 55-83\% oleic acid (C18:1), 3.5-21\% linoleic acid (C18:2) and 7.5-20\% palmitic acid (C16:0) (Kiritsakis et al., 1998). The three groups of peaks in Fig. 1b and c for the olive oil standards are TAG with various combinations of these three fatty acids at the $s n-1, s n-2$ and $s n-3$ positions of the glycerol backbone. The peak at 27.15 min (longest retention time (RT)) is a TAG with oleic acid at each position $(s n-1, s n-2$ and $s n-3)$. The left-most TAG peak (ret. time 25.76) is predominantly palmitic acid, but the shift in retention time compared to the C16:0 TAG standard suggests oleic acid or linoleic acid must also be present at one position.

Microorganisms are known to produce a wider range of mono-, diand triacylglycerides than higher plants with carbon chain length varying by more than six carbon atoms and a range of saturation states (Brown et al., 2009). However, it is uncommon to find a glycerolipid synthesized by any organism with individual fatty acids deviating by more than two carbon atoms, albeit saturation states can differ significantly (Brown et al., 2009). Therefore, the challenge of separating and quantifying all potentially possible glycerolipids was addressed by developing calibration ranges based on the residence time of each of the twenty even-chain length standards as described in Section 2.9.2 and further comparing these results to mass spectroscopy analysis of FAMEs derived from the extractable lipids (Section 2.8). 


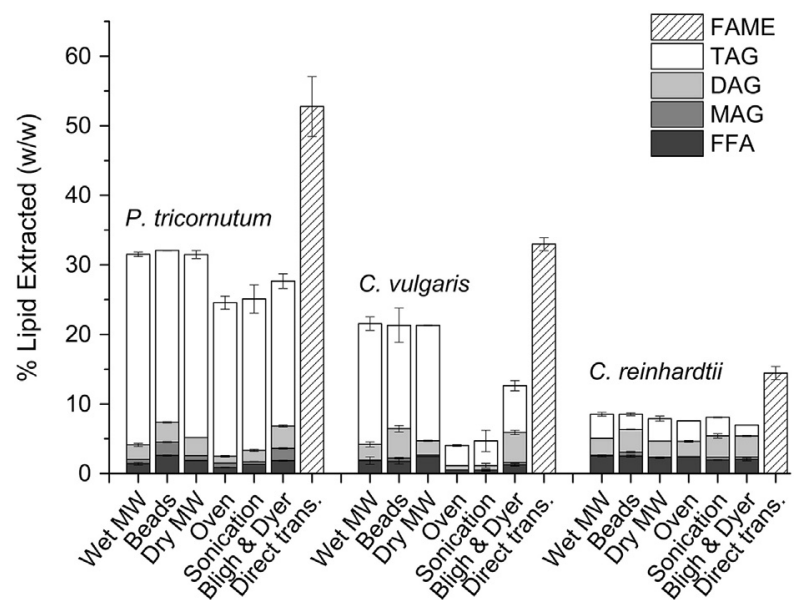

Fig. 2. Average and standard deviation of extractable lipid \% (w/w) using various cell disruption techniques on $P$. tricornutum, C. vulgaris and C. reinhardtii: Microwave extraction of wet biomass (Wet MW), bead beating (Beads), microwave extraction on dry biomass (Dry MW), heat induced extraction (Oven), sonication probe (Sonication), a modified Bligh and Dyer method and direct in situ transesterification for total biodiesel potential (Direct trans.) $(\mathrm{n}=3)$.

The described GC-FID analysis of extractable lipid provides information regarding the lipid class and chain length (cf. Fig. 1), however, it is not capable of chromatographically separating a number of the acylglycerides based on the degree of fatty acid chain saturation. This limitation was addressed to a large extent by transesterifying the lipid extract and comparing the FAME profile to the relative abundance of the lipid classes, based on chain length and saturation. The details are discussed in detail in Section 3.3.

\subsection{Comparison of various cell disruption and lipid extraction techniques}

To test the validity of microwave energy as a suitable and rapid method for cell disruption and lipid extraction, it was necessary to compare the results of the microwave technique to those from more traditional methods (Fig. 2). Historically, the Bligh and Dyer (1959) gravimetric method for quantifying lipid has been considered the standard for lipid extraction (Gouveia and Oliveira, 2009; Laurens et al., 2012b; Singh and Kumar, 1992; Teixeira, 2012). However, it has been shown that the Bligh and Dyer method can produce significantly lower estimates of lipid content, and this underestimation tends to increase significantly with increasing lipid content of the sample (Iverson et al., 2001). More recently, researchers have demonstrated that cell lysis by mechanical means such as sonication and bead beating aids in lipid extraction (Lee et al., 1998, 2010; Zheng et al., 2011). However, these techniques require significant processing time due to limitations of the instruments and extensive preparation of sample and materials. For example, biomass must first be frozen and lyophilized, requiring up to $48 \mathrm{~h}$ or more from the time of harvest until processing can commence, and often only one sample can be processed at a time. These factors can limit one's ability to acquire lipid profiles throughout the timecourse of culturing and implement adjustments as necessary. Furthermore, extensive processing times carry a greater risk of the sample composition changing between collection and analysis. For example, it has been shown that TAG can be degraded during dark hours in some algal cultures (Bigelow et al., 2011; Gardner et al., 2012) making long processing times undesirable.

Microwave extraction of lipid precursors from live culture required less than $2 \mathrm{~h}$ from time-of-harvest to generation of GC data and was shown to yield as much, if not more, lipid than the other techniques tested on these three organisms (Fig. 2). Further, relatively small volumes of culture (usually $<50 \mathrm{~mL}$ ) are necessary for each sample point, resulting in the ability to potentially collect multiple data points throughout even lab scale experiments.

Results from these techniques were also compared against results from direct in situ transesterification of live culture. Exhaustive direct in situ transesterification converts free and bound fatty acids into FAMEs (Laurens et al., 2012b), thereby generating larger amounts of FAMEs than the other techniques due to the additional conversion of fatty acids from non-extractable cellular sources (i.e. membrane bound lipids, chlorophyll, etc.).

It is important to assess potential losses or degradation of lipids due to the extraction technique. There was a concern that high heat generated during the microwave disruption process may result in thermal degradation of lipid compounds such as TAG. Hence, samples of olive oil were subjected to the microwave extraction process and compared to the untreated olive oil sample. Briefly, $3 \mathrm{~mL}$ of a $1 \mathrm{mg} / \mathrm{mL}$ (olive oil/ chloroform) mixture was microwaved for 10 min according to the protocol described in Section 2.9.5. One $\mathrm{mL}$ of this mixture was removed and analyzed by GC-FID against a control of the same concentration which had not been exposed to microwave heat. Chromatograms for the sample and control are shown in Fig. 1 (b and c). Statistical equivalence was determined for each response peak as described in Section 2.9 .6 with $95 \%$ confidence.

\subsection{Comparison of extractable lipid-derived FAMEs to total biodiesel potential}

Another significant benefit of this method is the ability to determine which fraction of total biodiesel potential was derived from extractable lipid precursors (e.g. FFA, MAG, DAG, TAG) as opposed to residual precursors (e.g. membrane lipids). Additionally, the lipid class itself can be determined by the carbon chain length of the extractable lipid-derived FAMEs. This advancement was achieved due to the relative simplicity of extracting lipids from live cultures using microwave energy, transesterifying the extract and quantifying both the extract and transesterified extract by GC-FID and GC-MS, respectively. This approach results in two chromatograms for each sample whose comparison allows for an estimate of the lipid class and carbon chain length of the extractable lipid precursors as well as the carbon chain length and saturation of the extractable lipidderived FAMEs. The comparison of the results of extractable lipidderived FAMEs with direct in situ transesterified FAMEs (Griffiths et al., 2010, which was modified here to allow for the processing of small quantities of live cultures), makes it possible to assess which fraction

Table 1

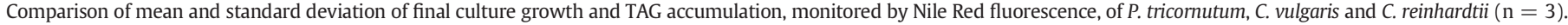

\begin{tabular}{|c|c|c|c|c|}
\hline Organism & $\begin{array}{l}\text { Dry weight } \\
\left(\mathrm{g} \mathrm{L}^{-1} ; \mathrm{DCW}\right)^{\mathrm{a}}\end{array}$ & $\begin{array}{l}\text { Final cell density } \\
\left(\times 10^{6} \text { cells } \mathrm{mL}^{-1}\right)\end{array}$ & $\begin{array}{l}\text { Final total Nile Red fluorescence } \\
\left(\times 10^{3} \text { units }\right)\end{array}$ & $\begin{array}{l}\text { Final Nile Red specific fluorescence } \\
\left.\text { (units cell }^{-1}\right)^{\mathrm{b}}\end{array}$ \\
\hline P. tricornutum & $0.18 \pm 0.06$ & $8.65 \pm 0.49$ & $9.71 \pm 0.27$ & $1.12 \pm 0.03$ \\
\hline C. vulgaris & $0.88 \pm 0.05$ & $200 \pm 10$ & $4.06 \pm 0.6$ & $0.02 \pm 0.003$ \\
\hline C. reinhardtii & $0.9 \pm 0.02$ & $7.55 \pm 0.3$ & $3.37 \pm 0.16$ & $0.45 \pm 0.003$ \\
\hline
\end{tabular}

a Dry cell weight (DCW) determined gravimetrically with lyophilized biomass.

b Calculated by fluorescence signal/cell density $\times 10,000$ (scaling factor). 
Table 2

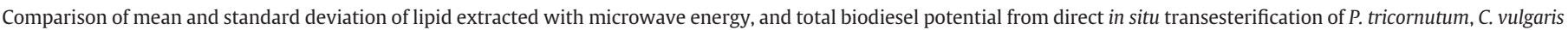
and $C$. reinhardtii $(\mathrm{n}=3$ ). All values expressed as \% (lipid/CDW).

\begin{tabular}{|c|c|c|c|c|c|c|}
\hline Organism & Free fatty acid (\%) ${ }^{a}$ & Mono-glyceride $(\%)^{\mathrm{a}}$ & Di-glyceride $(\%)^{\mathrm{a}}$ & Tri-glyceride $(\%)^{\mathrm{a}}$ & Sum of extracted $(\%)^{b}$ & Total biodiesel potential (\%) \\
\hline P. tricornutum & $1.4 \pm 0.2$ & $0.65 \pm 0.02$ & $2.08 \pm 0.22$ & $27.39 \pm 0.32$ & $31.51 \pm 0.33$ & $51.19 \pm 0.75$ \\
\hline C. vulgaris & $1.88 \pm 0.54$ & $0.06 \pm 0.01$ & $2.26 \pm 0.36$ & $17.35 \pm 0.95$ & $21.56 \pm 0.06$ & $32.96 \pm 0.93$ \\
\hline C. reinhardtii & $2.56 \pm 0.15$ & $0.07 \pm 0.01$ & $2.43 \pm 0.03$ & $3.46 \pm 0.28$ & $8.53 \pm 0.18$ & $14.45 \pm 0.95$ \\
\hline
\end{tabular}

a From microwave extraction of wet biomass.

b Sum of neutral lipid precursors - free fatty acids, mono, di, tri-glycerides.

c Total FAMEs from direct in situ transesterification.

of total biodiesel potential was likely derived from extractable lipid. The remaining difference between direct in situ transesterified FAMEs and extractable lipid-derived FAMEs is considered to be the residual fraction (e.g. membrane lipids). Further, the originating lipid class of the extractable lipid-derived FAMEs can be determined with relatively high confidence by comparing the carbon chain length of the molecule to the extractable lipid precursors quantified by GC-FID. This approach makes it possible to gain a comprehensive lipid assessment of a microalgae culture. It should be noted, that while the methods described here are capable of detecting a multitude of lipid compounds, e.g. cyclopropane fatty acids or amide-linked fatty acids (sphingolipids), by mass-spectroscopy, such compounds were not detected in significant abundance in any of the cultures. If these compounds are present and quantifiable in samples, they would be grouped into the "Other" category in the reported values. Additionally, two different transesterification techniques were used to derive total FAMEs versus extractable FAMEs. The direct in situ transesterification (Section 2.7) was used for total cellular fatty acid conversion to FAMEs. This method uses both a base (sodium methoxide) and an acid (boron tri-fluoride in methanol) to fully transesterify all cellular fatty acid compounds into FAMEs. The sequential addition of a basic and acidic catalyst has been shown to improve the efficiency of direct transesterification when water is present, as is the case when using live cultures (Griffiths et al., 2010). The basic catalyst, in the presence of water, promotes the saponification of glycerolipids via alkaline hydrolysis, thereby cleaving the ester bonds between fatty acids and glycerol. The subsequent addition of acid catalyst increases the rate of esterification of liberated free fatty acids. These combined steps reduce the detrimental effects of water and result in faster and more efficient conversion of lipids to FAMEs (Griffiths et al., 2010). Extractable lipid compounds were transesterified using only acid $(\mathrm{HCl})$ as a catalyst (Section 2.8). This was determined to be sufficient because there was no significant amount of water present in the extract containing the extractable lipid. Both techniques were compared using the precursor lipid extract and no yield differences were found. Since the acid only method is faster and uses less material, it was determined to be more suitable.

\subsubsection{Phaeodactylum tricornutum}

P. tricornutum was cultured as previously described by Gardner et al. (2012) and harvested at peak TAG accumulation, as monitored by Nile Red fluorescence (Table 1). Lipids were extracted by the microwave extraction method described in Section 2.6.1. Total FAMEs were determined as described in Section 2.7, and FAMEs derived from extractable lipid were determined as described in Section 2.8. Total FAME was $51.2 \%(\mathrm{w} / \mathrm{w})$ and the sum of all extractable lipids was $31.5 \%(\mathrm{w} / \mathrm{w})$ with TAG contributing the majority at $27.4 \%(\mathrm{w} /$ w) or $87 \%$ of the extract (Table 2). Fig. 3 shows the complete FAME profile for P. tricornutum. Results from direct in situ transesterification indicate that under these growth conditions this organism preferentially synthesized C16:1 and C16:0 lipid compounds. Total C16:1 and C16:0 FAMEs were $24.8 \%(\mathrm{w} / \mathrm{w})$ and $14.7 \%(\mathrm{w} / \mathrm{w})$ respectively (Table 4). The fractions of total $C_{16}$ FAMEs from extractable lipids were $54.5 \%$ for $\mathrm{C} 16: 1$ and $51.8 \%$ for $\mathrm{C} 16: 0$ (Table 4 ). The sum of all $C_{16}$ FAMEs derived from extractable lipid was $21.1 \pm 0.3 \%(\mathrm{w} / \mathrm{w})$ (Table 4$)$ and total $\mathrm{C}_{16}$ TAG was $21.4 \pm 0.8 \%(\mathrm{w} / \mathrm{w})$ (Table 3), indicating that these $C_{16}$ FAMEs derived from extractable lipid potentially originated as $\mathrm{C}_{16}$ TAG. Additionally, Fig. 3 shows that all unsaturated $\mathrm{C}_{18}$ FAMEs were derived from extractable lipid. The sum of these unsaturated $\mathrm{C}_{18}$ FAMEs was $3.9 \pm 0.35 \%(\mathrm{w} / \mathrm{w})$ (Table 4$)$ and total $\mathrm{C}_{18}$ TAG was $3.4 \pm$ $0.04 \%(w / w)$ (Table 3$)$, indicating that the majority of unsaturated $C_{18}$ FAMEs originated as $\mathrm{C}_{18}$ TAG. Furthermore, under these conditions $P$. tricornutum produced $4.52 \pm 0.07 \%(\mathrm{w} / \mathrm{w})$ eicosapentaenoic acid (EPA) (Table 4), which is a valuable omega-3 fatty acid marketed for its suggested beneficial effects on human health (Alonso et al., 1996). Over half of the total EPA produced was derived from extractable lipid (Table 4), all of which originated as $C_{20}$ TAG (Table 3). Of the $1.99 \pm$ $0.02 \%(\mathrm{w} / \mathrm{w})$ C14:0 FAMEs produced by this culture, 58\% were derived from extractable lipid, of which $57 \%$ originated as $\mathrm{C}_{14}$ TAG and $43 \%$ originated as $\mathrm{C}_{14}$ MAG.

\subsubsection{Chlorella vulgaris}

Cultures of $C$. vulgaris were sparged continuously with air amended with $5 \% \mathrm{CO}_{2}$. Once peak TAG accumulation was reached, as monitored by Nile Red fluorescence (Table 1), the cultures were harvested for lipid extraction (Section 2.6.1), total FAMEs determination (Section 2.7) and an estimate of FAMEs derived from extractable lipids (Section 2.8). Fig. 4 shows the complete FAME profile for C. vulgaris. Interestingly, this fresh water green microalga preferentially synthesized unsaturated $C_{18}$ fatty acids under the culture conditions employed here, compared to $P$. tricornutum which predominantly synthesized unsaturated $C_{16}$ fatty acids. Total FAME content for $C$. vulgaris was $33 \%(\mathrm{w} / \mathrm{w})$ and the sum of all extractable lipids was $21.6 \%(\mathrm{w} / \mathrm{w})$ with TAG contributing the majority at $17.4 \%(\mathrm{w} / \mathrm{w})$ or $80.6 \%$ of the total extract (Table 2). Twenty two percent (w/w) of total FAME was unsaturated $\mathrm{C}_{18}$ fatty acids, of which $66 \%$ were derived from extractable lipid (Table 4). The sum of these unsaturated $C_{18}$ FAMEs derived from extractable lipids was $14.7 \pm 0.2 \%\left(\mathrm{w} / \mathrm{w}\right.$ ) (Table 4 ) and total $\mathrm{C}_{18}$

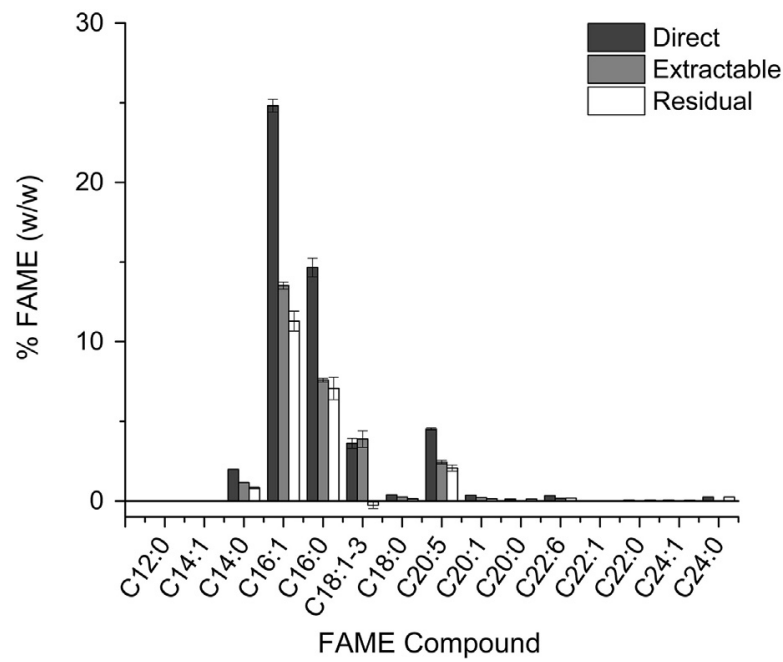

Fig. 3. Average and standard deviation of the FAME profile for $P$. tricornutum comparing direct in situ transesterification of all fatty acids (Direct) to FAMEs derived from only extractable lipid precursors (Extractable). The residual fraction is the difference between direct and extractable transesterification $(n=3)$. 
Table 3

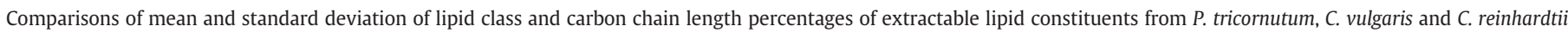
$(n=3)$. All values expressed as \% (lipid/CDW).

\begin{tabular}{|c|c|c|c|c|c|c|}
\hline Organism & $\mathrm{C}_{12}$ & $\mathrm{C}_{14}$ & $\mathrm{C}_{16}$ & $\mathrm{C}_{18}$ & $\mathrm{C}_{20}$ & $\mathrm{C}_{22}$ \\
\hline \multicolumn{7}{|l|}{ Free fatty acid (\%) ${ }^{\mathrm{a}}$} \\
\hline P. tricornutum & $\mathrm{N} / \mathrm{D}$ & $0.25 \pm 0.02$ & $1 \pm 0.19$ & $0.13 \pm 0$ & $0.01 \pm 0.01$ & $\mathrm{~N} / \mathrm{D}$ \\
\hline C. vulgaris & $0.11 \pm 0.03$ & $0.23 \pm 0.04$ & $0.57 \pm 0.18$ & $0.92 \pm 0.28$ & $0.05 \pm 0.02$ & $\mathrm{~N} / \mathrm{D}$ \\
\hline C. reinhardtii & $\mathrm{N} / \mathrm{D}$ & $\mathrm{N} / \mathrm{D}$ & $1.13 \pm 0.05$ & $1.43 \pm 0.11$ & $\mathrm{~N} / \mathrm{D}$ & $\mathrm{N} / \mathrm{D}$ \\
\hline \multicolumn{7}{|l|}{ Mono-glyceride (\%) } \\
\hline P. tricornutum & N/D & $0.56 \pm 0.04$ & $0.04 \pm 0.03$ & $0.06 \pm 0.01$ & N/D & $\mathrm{N} / \mathrm{D}$ \\
\hline C. vulgaris & N/D & $\mathrm{N} / \mathrm{D}$ & $\mathrm{N} / \mathrm{D}$ & $0.06 \pm 0.01$ & $\mathrm{~N} / \mathrm{D}$ & $\mathrm{N} / \mathrm{D}$ \\
\hline C. reinhardtii & $\mathrm{N} / \mathrm{D}$ & $\mathrm{N} / \mathrm{D}$ & $0.02 \pm 0.01$ & $0.06 \pm 0.03$ & $\mathrm{~N} / \mathrm{D}$ & $\mathrm{N} / \mathrm{D}$ \\
\hline \multicolumn{7}{|l|}{ Di-glyceride (\%) ${ }^{\mathrm{a}}$} \\
\hline P. tricornutum & $0.39 \pm 0.08$ & $0.02 \pm 0.01$ & $1.06 \pm 0.04$ & $0.61 \pm 0.19$ & $\mathrm{~N} / \mathrm{D}$ & $\mathrm{N} / \mathrm{D}$ \\
\hline C. vulgaris & $0.24 \pm 0.03$ & $0.07 \pm 0.01$ & $0.48 \pm 0.09$ & $1.47 \pm 0.24$ & $\mathrm{~N} / \mathrm{D}$ & $\mathrm{N} / \mathrm{D}$ \\
\hline C. reinhardtii & $0.24 \pm 0$ & $0.38 \pm 0.02$ & $0.45 \pm 0.01$ & $1.36 \pm 0.04$ & $\mathrm{~N} / \mathrm{D}$ & $\mathrm{N} / \mathrm{D}$ \\
\hline \multicolumn{7}{|l|}{ Tri-glyceride (\%) ${ }^{\mathrm{a}}$} \\
\hline P. tricornutum & N/D & $0.73 \pm 0.06$ & $21.38 \pm 0.81$ & $3.4 \pm 0.04$ & $1.87 \pm 0.47$ & $\mathrm{~N} / \mathrm{D}$ \\
\hline C. vulgaris & N/D & $0.1 \pm 0.1$ & $4.29 \pm 0.5$ & $12.81 \pm 0.35$ & $0.15 \pm 0.07$ & $\mathrm{~N} / \mathrm{D}$ \\
\hline C. reinhardtii & N/D & $0.01 \pm 0.01$ & $2.05 \pm 0.12$ & $1.4 \pm 0.17$ & N/D & $\mathrm{N} / \mathrm{D}$ \\
\hline
\end{tabular}

N/D - not detected.

a From microwave extraction of wet biomass.

Table 4

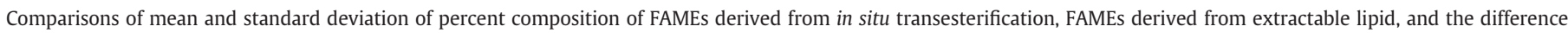
being reported as the residual fraction of total FAME for P. tricornutum, $C$. vulgaris and C. reinhardtii $(\mathrm{n}=3$ ). All values expressed as \% (lipid/CDW).

\begin{tabular}{|c|c|c|c|c|c|c|c|c|c|c|c|}
\hline Organism & $\mathrm{C} 14: 0$ & C16:1 & C16:0 & $\mathrm{C} 18: 1-3^{\mathrm{b}}$ & C18:0 & C20:5 & C20:1 & C20:0 & $\mathrm{C} 22: 6$ & $\mathrm{C} 24: 0$ & Other $^{\mathrm{c}}$ \\
\hline \multicolumn{12}{|c|}{ Direct trans-esterification \% lipid content (w/w) } \\
\hline P. tricornutum & $1.99 \pm 0.02$ & $24.81 \pm 0.4$ & $14.66 \pm 0.59$ & $3.62 \pm 0.32$ & $0.39 \pm 0.01$ & $4.52 \pm 0.07$ & $0.37 \pm 0.01$ & $0.12 \pm 0$ & $0.34 \pm 0.01$ & $0.25 \pm 0$ & $0.13 \pm 0.02$ \\
\hline C. vulgaris & $0.04 \pm 0$ & $3.07 \pm 0.07$ & $6.88 \pm 0.17$ & $22.18 \pm 0.72$ & $0.67 \pm 0.02$ & $\mathrm{~N} / \mathrm{D}$ & $0.05 \pm 0.03$ & $0.04 \pm 0$ & $\mathrm{~N} / \mathrm{D}$ & $0.05 \pm 0$ & $0.03 \pm 0.02$ \\
\hline C. reinhardtii & $0.04 \pm 0$ & $2.01 \pm 0.1$ & $3.35 \pm 0.22$ & $8.64 \pm 0.53$ & $0.33 \pm 0.03$ & $\mathrm{~N} / \mathrm{D}$ & $0.07 \pm 0.04$ & $0.05 \pm 0.03$ & $\mathrm{~N} / \mathrm{D}$ & $\mathrm{N} / \mathrm{D}$ & $0.02 \pm 0.0$ \\
\hline \multicolumn{12}{|c|}{$\%$ Extractable lipid fraction $(\mathrm{w} / \mathrm{w})^{\mathrm{a}}$} \\
\hline P. tricornutum & $1.16 \pm 0.04$ & $13.52 \pm 0.22$ & $7.59 \pm 0.12$ & $3.89 \pm 0.52$ & $0.25 \pm 0.02$ & $2.45 \pm 0.12$ & $0.23 \pm 0.01$ & $\mathrm{~N} / \mathrm{D}$ & $0.16 \pm 0.02$ & $\mathrm{~N} / \mathrm{D}$ & $\mathrm{N} / \mathrm{D}$ \\
\hline C. vulgaris & $\mathrm{N} / \mathrm{D}$ & $2.57 \pm 0.16$ & $4.04 \pm 1.08$ & $14.72 \pm 0.19$ & $0.65 \pm 0.05$ & $\mathrm{~N} / \mathrm{D}$ & $\mathrm{N} / \mathrm{D}$ & $\mathrm{N} / \mathrm{D}$ & $\mathrm{N} / \mathrm{D}$ & $\mathrm{N} / \mathrm{D}$ & $\mathrm{N} / \mathrm{D}$ \\
\hline C. reinhardtii & $0.03 \pm 0$ & $1.99 \pm 0.31$ & $1.7 \pm 0.14$ & $4.28 \pm 0.27$ & $0.03 \pm 0$ & $\mathrm{~N} / \mathrm{D}$ & $0.04 \pm 0.02$ & $0.03 \pm 0.02$ & $\mathrm{~N} / \mathrm{D}$ & $\mathrm{N} / \mathrm{D}$ & $\mathrm{N} / \mathrm{D}$ \\
\hline \multicolumn{12}{|c|}{ \% Residual lipid fraction (w/w) } \\
\hline P. tricornutum & $0.83 \pm 0.06$ & $11.29 \pm 0.62$ & $7.07 \pm 0.7$ & $-0.27 \pm 0.2$ & $0.14 \pm 0.03$ & $2.07 \pm 0.19$ & $0.14 \pm 0.01$ & $0.12 \pm 0$ & $0.18 \pm 0.02$ & $0.25 \pm 0$ & $0.13 \pm 0.02$ \\
\hline C. vulgaris & $0.04 \pm 0$ & $0.49 \pm 0.05$ & $2.84 \pm 0.42$ & $7.46 \pm 1.1$ & $0.02 \pm 0.02$ & $\mathrm{~N} / \mathrm{D}$ & $0.05 \pm 0.03$ & $0.04 \pm 0$ & $\mathrm{~N} / \mathrm{D}$ & $0.05 \pm 0$ & $0.03 \pm 0.02$ \\
\hline C. reinhardtii & $0.02 \pm 0$ & $0.02 \pm 0.71$ & $1.65 \pm 0.83$ & $4.36 \pm 0.21$ & $0.3 \pm 0.03$ & $\mathrm{~N} / \mathrm{D}$ & $0.04 \pm 0.06$ & $0.01 \pm 0.01$ & $\mathrm{~N} / \mathrm{D}$ & $\mathrm{N} / \mathrm{D}$ & $0.02 \pm 0.0$ \\
\hline
\end{tabular}

N/D - not detected.

a From microwave extraction of wet biomass, followed by transesterification of extracted lipid.

b C18:1, C18:2, and C18:3 taken together.

c Sum of other compounds detected.

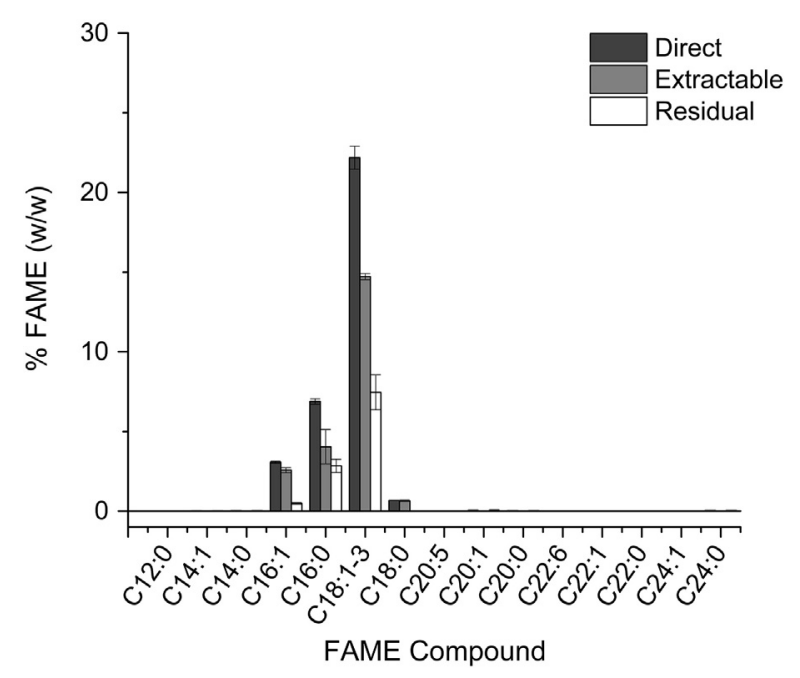

Fig. 4. Average and standard deviation of the FAME profile for C. vulgaris comparing direct in situ transesterification of all fatty acids (Direct) to FAMEs derived from only extractable lipid precursors (Extractable). The residual fraction is the difference between direct and extractable transesterification $(n=3)$.
TAG was $12.8 \pm 0.35 \%(\mathrm{w} / \mathrm{w})$ (Table 3$)$. This indicates that the majority of unsaturated $C_{18}$ FAMEs were derived from extractable lipid and originated as $\mathrm{C}_{18}$ TAG, with the remainder originating as $\mathrm{C}_{18}$ DAG $(1.5 \% \mathrm{w} / \mathrm{w})$ and $\mathrm{C}_{18}$ FFA (1\% w/w) (Table 3). Furthermore, $10 \%(\mathrm{w} / \mathrm{w})$ of total FAMEs for this culture of $C$. vulgaris were $C_{16}$ fatty acid methyl ester, with $6.6 \%(\mathrm{w} / \mathrm{w})$ derived from extractable lipid. Table 3 shows that $65 \%$ of the $C_{16}$ FAMEs derived from extractable lipid were originally $C_{16}$ TAG with the remainder originating as $C_{16}$ DAG and $C_{16}$ FFA.

\subsubsection{Chlamydomonas reinhardtii}

The model Chlorophyte, $C$. reinhardtii, was cultured as previously reported by Gardner et al. (2013) until peak TAG accumulation was achieved as monitored by Nile Red fluorescence (Table 1 ). The cultures were harvested and lipid was extracted using the microwave extraction method described in Section 2.6.1. Total FAMEs were determined as described in Section 2.7, and FAMEs derived from extractable lipid were determined as described in Section 2.8. Total FAME content was determined to be $14.5 \%(\mathrm{w} / \mathrm{w})$ and the sum of all extractable lipids was $8.5 \%(\mathrm{w} / \mathrm{w})$ with TAG contributing the majority at $3.5 \%(\mathrm{w} / \mathrm{w})$ or $41.2 \%$ of the extract and DAG accounting for $2.4 \%(\mathrm{w} / \mathrm{w})$ or $28.2 \%$ of the extract (Table 2 ). C. reinhardtii is not known as an organism capable of producing a significant amount of TAG, and therefore is not typically regarded as a contender for industrial production of algal biofuel (Hu et al., 2008). However, it is widely studied and 


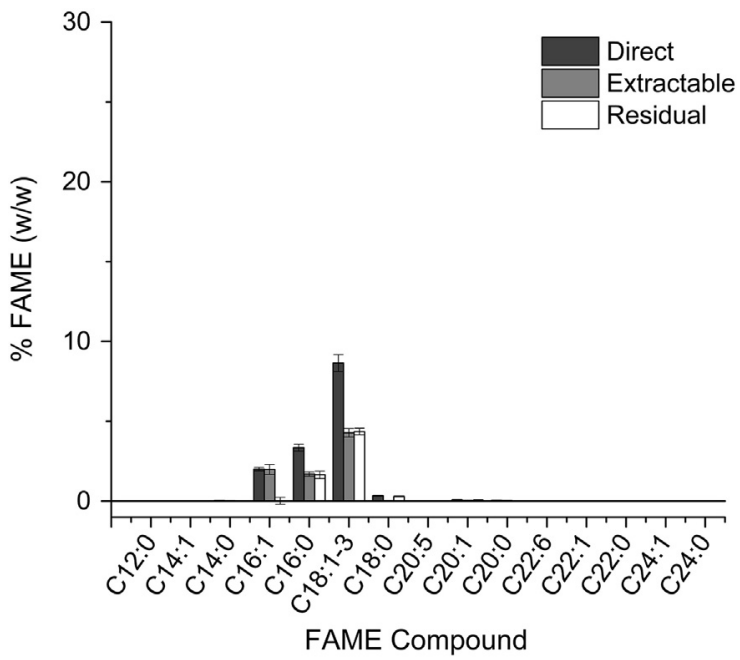

Fig. 5. Average and standard deviation of the FAME profile for $C$. reinhardtii comparing direct in situ transesterification of all fatty acids (Direct) to FAMEs derived from only extractable lipid precursors (Extractable). The residual fraction is the difference between direct and extractable transesterification $(n=3)$.

one of the first microalgae to have its genome fully sequenced. Thus, it is still a reasonable candidate for future research regarding lipid profile and metabolite analysis. Fig. 5 shows the complete FAME profile for C. reinhardtii.

Similar to C. vulgaris, $C$. reinhardtii predominantly synthesized unsaturated $\mathrm{C}_{18}$ lipid compounds. Total unsaturated $\mathrm{C}_{18}$ FAMEs were $8.6 \%(\mathrm{w} / \mathrm{w})$, of which $\sim 50 \%$ were derived from extractable lipid. Unlike C. vulgaris, in this culture of $C$. reinhardtii, not all of the $\mathrm{C}_{18}$ FAMEs derived from extractable lipid came from $\mathrm{C}_{18}$ TAG. Instead, $\sim 33 \%$ were originally $\mathrm{C}_{18}$ FFA, $\sim 33 \% \mathrm{C}_{18}$ DAG and $33 \% \mathrm{C}_{18}$ TAG (Table 3). All unsaturated $C_{16}$ FAME compounds were derived from extractable lipid. However, the original source of these compounds is ambiguous. Total unsaturated $C_{16}$ FAMEs derived from extractable lipid were $1.99 \pm 0.31 \%(\mathrm{w} / \mathrm{w})$, total $\mathrm{C}_{16}$ FFA were $1.0 \pm 0.19 \%$ $(\mathrm{w} / \mathrm{w})$, total $\mathrm{C}_{16}$ DAG were $0.45 \pm 0.01 \%(\mathrm{w} / \mathrm{w})$ and total $\mathrm{C}_{16}$ TAG were $2.05 \pm 0.12 \%(\mathrm{w} / \mathrm{w})$. Unambiguously discerning which fraction of these extractable lipid precursors was responsible for the unsaturated $\mathrm{C}_{16}$ FAMEs is not possible with this method and will require additional method development.

\section{Conclusion}

We describe a new rapid method for the efficient extraction of lipids from live cultures of microalgae for the purpose of quantifying the lipid content and characterizing the lipid carbon chain length and saturation. Additionally, we developed methods to determine the fraction of total biodiesel potential (as FAME) derived either from extractable lipid or from the residual fraction. Furthermore, the method can frequently determine from which lipid class (FFA, MAG, DAG, TAG) a particular FAME was derived. Since properties of biodiesel depend heavily on the length and degree of saturation of the FAME, the methods described here can assist in 'fine-tuning' the final product, be it biodiesel or a higher value product, through the choice of certain algae or growth conditions.

Specifically, here we demonstrate the usefulness of this method by demonstrating differences in lipid profiles for three frequently studied microalgae. It is demonstrated that the marine diatom $P$. tricornutum preferentially produced unsaturated $C_{16}$ lipid compounds, whereas the two freshwater green microalgae, $C$. vulgaris and $C$. reinhardtii, predominantly synthesized unsaturated $C_{18}$ compounds. From an industrial standpoint, it will be beneficial to choose the appropriate algae and culture conditions to produce the largest possible amount of biodiesel with the appropriate FAME profile or to screen for algal products with higher value than biodiesel. For instance $P$. tricornutum was shown to produce an omega-3 fatty acid, specifically eicosapentaenoic acid (C20:5), which has been suggested to benefit human health. This method has determined that these compounds were primarily derived from triacylglyceride storage molecules.

In order to apply the methods described here to other algae, plants or different culturing conditions, verification of extraction and transesterification efficacy will have to be conducted. Such checks are fairly quick and are described in detail for the algae and culturing conditions employed here.

\section{Financial disclosure}

This material is based upon work supported by the National Science Foundation (NSF) under CHE-1230632. A portion of this research was supported by the U.S. Department of Energy (DOE) Office of Energy Efficiency and Renewable Energy (EERE) Biomass Program under Contract Nos. DE-EE0003136 and DE-EE0005993. Support for EL and RDG was also provided by the NSF IGERT Program in Geobiological Systems (DGE 0654336). Instrumental support was provided through the Center for Biofilm Engineering (CBE) at Montana State University (MSU) as well as by the Environmental and Biofilm Mass Spectrometry Facility (EBMSF) funded through DURIP Contract Number: W911NF0510255 and the MSU Thermal Biology Institute from the NASA Exobiology Program Project NAG5-8807.

\section{References}

Alonso, D.L., Segura, C.I., Grima, E.M., 1996. First insights into improvement of eicosapentanoic acid content in Phaeodactylum tricornutum (Bacillariophyceae) by induced mutagenesis. J. Phycol. 32, 339-345.

Bigelow, N.W., Hardin, W.R., Barker, J.P., Ryken, S. a, Macrae, A.C., Cattolico, R.A., 2011. A comprehensive GC-MS sub-microscale assay for fatty acids and its applications. J. Am. Oil Chem. Soc. 88, 1329-1338.

Bligh, E.G., Dyer, W.J., 1959. A rapid method of total lipid extraction and purification. Can. J. Biochem. Physiol. 37, 911-917.

Brown, A.P., Slabas, A.R., Rafferty, J.B., 2009. Fatty acid biosynthesis in plants - metabolic pathways, structure and organization. In: Govindjee, Wada, H., Murata, N. (Eds.), Lipids in Photosynthesis: Essential and Regulatory Functions. Advances in Photosynthesis and Respiration, pp. 11-34.

Chen, W., Zhang, C., Song, L., Sommerfeld, M., Hu, Q., 2009. A high throughput Nile red method for quantitative measurement of neutral lipids in microalgae. J. Microbiol. Methods 77, 41-47.

Chisti, Y., 2007. Biodiesel from microalgae. Biotechnol. Adv. 25, 294-306.

Cooksey, K.E., Guckert, J.B., Williams, S.A., Callis, P.R., 1987. Fluorometric determination of the neutral lipid content of microalgal cells using Nile Red. J. Microbiol. Methods 6, 333-345.

Da Silva, T.L., Reis, A., Medeiros, R., Oliveira, A.C., Gouveia, L., 2009. Oil production towards biofuel from autotrophic microalgae semicontinuous cultivations monitorized by flow cytometry. Appl. Biochem. Biotechnol. 159, 568-578.

Demirbas, A., 2007. Importance of biodiesel as transportation fuel. Energy Policy 35, 4661-4670.

Dismukes, G.C., Carrieri, D., Bennette, N., Ananyev, G.M., Posewitz, M.C., 2008. Aquatic phototrophs: efficient alternatives to land-based crops for biofuels. Curr. Opin. Biotechnol. 19, 235-240.

EIA, 2012. How Dependent Are We on Foreign Oil? [WWW Document]. U.S. Energy Information Administration. (URL http://www.eia.gov/energy_in_brief/foreign_oil_ dependence.cfm)

Elsey, D., Jameson, D., Raleigh, B., Cooney, M.J., 2007. Fluorescent measurement of microalgal neutral lipids. J. Microbiol. Methods 68, 639-642.

Eustance, E., Gardner, R.D., Moll, K., Menicucci, J., Gerlach, R., Peyton, B.M., 2013. Growth, nitrogen utilization and biodiesel potential for two chlorophytes grown on ammonium or nitrate. J. Appl. Phycol. http://dx.doi.org/10.1007/s10811-0130008-5 (in press).

Ferrell, J., Sarisky-Reed, V., 2010. National Algal Biofuels Technology Roadmap. U.S. Department of Energy's Office of Fuels Development.

Gardner, R., Peters, P., Peyton, B., Cooksey, K.E., 2011. Medium pH and nitrate concentration effects on accumulation of triacylglycerol in two members of the chlorophyta. J. Appl. Phycol. 23, 1005-1016.

Gardner, R.D., Cooksey, K.E., Mus, F., Macur, R., Moll, K., Eustance, E., Carlson, R.P., Gerlach, R., Fields, M.W., Peyton, B.M., 2012. Use of sodium bicarbonate to stimulate triacylglycerol accumulation in the chlorophyte Scenedesmus sp. and the diatom Phaeodactylum tricornutum. J. Appl. Phycol. 1311-1320.

Gardner, R.D., Lohman, E., Gerlach, R., Cooksey, K.E., Peyton, B.M., 2013. Comparison of $\mathrm{CO}(2)$ and bicarbonate as inorganic carbon sources for triacylglycerol and starch accumulation in Chlamydomonas reinhardtii. Biotechnol. Bioeng. 110, 87-96. 
Gouveia, L., Oliveira, A.C., 2009. Microalgae as a raw material for biofuels production. J. Ind. Microbiol. Biotechnol. 36, 269-274.

Greenwell, H.C., Laurens, L.M.L., Shields, R.J., Lovitt, R.W., Flynn, K.J., 2010. Placing microalgae on the biofuels priority list: a review of the technological challenges. J. R. Soc. Interface 7, 703-726.

Griffiths, M.J., Van Hille, R.P., Harrison, S.T.L., 2010. Selection of direct transesterification as the preferred method for assay of fatty acid content of microalgae. Lipids 45, 1053-1060.

Groom, M.J., Gray, E.M., Townsend, P. a, 2008. Biofuels and biodiversity: principles for creating better policies for biofuel production. Conserv. Biol. 22, 602-609.

Guckert, J.B., Cooksey, K.E., 1990. Triglyceride accumulation and fatty acid profile changes in Chlorella (Chlorophyta) during high pH-induced cell inhibition. J. Phycol. 26, 72-79.

Guckert, J.B., Cooksey, K.E., Jackson, L., 1988. Lipid solvent systems are not equivalent for analysis of lipid classes in the microeukaryotic green-alga, Chlorella. J. Microbiol. Methods 8, 139-149.

Harris, E.H., 1989. The Chlamydomonas Sourcebook: A Comprehensive Guide to Biology and Laboratory Use. Academic Press, San Diego.

Hill, J., Nelson, E., Tilman, D., Polasky, S., Tiffany, D., 2006. Environmental, economic, and energetic costs and benefits of biodiesel and ethanol biofuels. Proc. Natl. Acad. Sci. U. S. A. 103, 11206-11210.

Hu, Q., Sommerfeld, M., Jarvis, E., Ghirardi, M., Posewitz, M., Seibert, M., Darzins, A. 2008. Microalgal triacylglycerols as feedstocks for biofuel production: perspectives and advances. Plant J. 54, 621-639.

Hunter-Cevera, J.C., Boussiba, S., Cuello, J.L., Duke, C.S., Efroymson, R.A., Golden, S.S., Holmgren, J., Johnson, D.L., Jones, M.E., Smith, V.H., Steger, C., Stephanapoulos, G.N., Walker, L.P., Williams, E., Zimba, P.V., 2012. Sustainable development of algal biofuels committee on the sustainable development of algal biofuels. Board on Agriculture and Natural Resources. Board on Energy and Environmental Systems.

Iverson, S.J., Lang, S.L., Cooper, M.H., 2001. Comparison of the Bligh and Dyer and Folch methods for total lipid determination in a broad range of marine tissue. Lipids 36, 1283-1287.

Kiritsakis, A.K., Lenart, E.B., Willet, W.C., Hernandez, R.J., 1998. Olive Oil: from the Tree to the Table, 2nd ed. Food \& Nutrition Press, Trumbull, CT.

Knothe, G., 2005. Dependence of biodiesel fuel properties on the structure of fatty acid alkyl esters. Fuel Process. Technol. 86, 1059-1070.

Laurens, L., Quinn, M., Van Wychen, S., Templeton, D.W., Wolfrum, E.J., 2012a. Accurate and reliable quantification of total microalgal fuel potential as fatty acid methyl esters by in situ transesterification. Anal. Bioanal. Chem. 403, 167-178.

Laurens, L., Dempster, T. a, Jones, H.D.T., Wolfrum, E.J., Van Wychen, S., McAllister, J.S.P., Rencenberger, M., Parchert, K.J., Gloe, L.M., 2012b. Algal biomass constituent analysis: method uncertainties and investigation of the underlying measuring chemistries. Anal. Chem. 84, 1879-1887.

Lee, S.J., Yoon, B., Oh, H., 1998. Rapid method for the determination of lipid from the green alga Botryococcus braunii. 12, 553-556.
Lee, J.-Y., Yoo, C., Jun, S.-Y., Ahn, C.-Y., Oh, H.-M., 2010. Comparison of several methods for effective lipid extraction from microalgae. Bioresour. Technol. 101, S75-S77 (Suppl.)

Liu, J., Huang, J., Sun, Z., Zhong, Y., Jiang, Y., Chen, F., 2011. Differential lipid and fatty acid profiles of photoautotrophic and heterotrophic Chlorella zofingiensis: assessment of algal oils for biodiesel production. Bioresour. Technol. 102, 106-110.

Martino, A. De, Meichenin, A., Shi, J., Pan, K., Bowler, C., 2007. Genetic and phenotypic characterization of Phaeodactylum tricornutum (Bacillariophyceae) accessions 1 J. Phycol. 43, 992-1009.

Merchant, S.S., Prochnik, S.E., Vallon, O., Harris, E.H., Karpowicz, S.J., et al., 2007. The Chlamydomonas genome reveals the evolution of key animal and plant functions. Science (New York, N.Y.) 318, 245-250.

Nichols, H., Bold, H., 1965. Trichosarcina polymorpha gen. et sp. nov. J. Phycol. 1, 34-38

Patil, P.D., Reddy, H., Muppaneni, T., Mannarswamy, A., Schuab, T., Holguin, F.O. Lammers, P., Nirmalakhandan, N., Cooke, P., Deng, S.G., 2012. Power dissipation in microwave-enhanced in situ transesterification of algal biomass to biodiesel. Green Chem. 14, 809-818.

Prabakaran, P., Ravindran, a D., 2011. A comparative study on effective cell disruption methods for lipid extraction from microalgae. Lett. Appl. Microbiol. 53, 150-154.

Provasoli, L., McLaughlin, J., Droop, M., 1957. The development of artificial media for marine algae. Arch. Microbiol. 25.

Richter, S.J., Richter, C., 2002. A method for determining equivalence in industrial applications. Qual. Eng. 14, 375-380.

Sheehan, J., 1998. A Look Back at the U.S. Department of Energy's Aquatic Species Program: Biodiesel from Algae. U.S. Department of Energy's Office of Fuels Development.

Singh, Y., Kumar, H.D., 1992. Lipid and hydrocarbon production by Botryococcus spp. under nitrogen limitation and anaerobiosis. 8, 121-124.

Spiekermann, P., Lerchl, J., Beckmann, C., Kilian, O., Kroth, P.G., Boland, W., Za, U., Heinz E., 2003. New insight into Phaeodactylum tricornutum fatty acid metabolism. Cloning and Functional Characterization of Plastidial and Microsomal $\Delta 12$-Fatty Acid Desaturases 1 [w], 131, pp. 1648-1660.

Stephenson, A.L., Dennis, J.S., Howe, C.J., Scott, S.A., Smith, A.G., 2010. Influence of nitrogen-limitation regime on the production by Chlorella vulgaris of lipids for biodiesel feedstocks. 1, 47-58.

Teixeira, R.E., 2012. Energy-efficient extraction of fuel and chemical feedstocks from algae. Green Chem. 14, 419.

Valenzuela, J., Mazurie, A., Carlson, R.P., Gerlach, R., Cooksey, K.E., Peyton, B.M., Fields M.W., 2012. Potential role of multiple carbon fixation pathways during lipid accumulation in Phaeodactylum tricornutum. Biotechnol. Biofuels 5, 40.

Xue, J., Grift, T.E., Hansen, A.C., 2011. Effect of biodiesel on engine performances and emissions. Renewable Sustainable Energy Rev. 15, 1098-1116.

Zheng, H., Yin, J., Gao, Z., Huang, H., Ji, X., Dou, C., 2011. Disruption of Chlorella vulgaris cells for the release of biodiesel-producing lipids: a comparison of grinding ultrasonication, bead milling, enzymatic lysis, and microwaves. Appl. Biochem. Biotechnol. 164, 1215-1224. 